\title{
Whatsapp Group: Media Komunikasi Orang Tua Dan Guru
}

\author{
Fitri Yana ${ }^{1}$, Inayatillah², Maya Agustina ${ }^{3}$ \\ STAIN Teuku Dirundeng Meulaboh1,2,3 \\ (Yanaf5921@gmail.com) (mayaagustn@staindirundeng.ac.id)
}

\begin{abstract}
With the development of technology and the emergence of various communication platforms, interaction can become easier. Especially in the online learning period, almost 90\% of educational and non-educational interactions are carried out through WhatsApp Groups. The purpose of this paper is to find out directly the use of WhatsApp Groups in building communication between parents and teachers and to find out the obstacles faced by parents and teachers in using WhatsApp Groups at SD IT Teuku Umar. This type of research is field research (field research). Data collection techniques used are interviews and documentation. The data analysis technique used is descriptive analysis. The results showed that the use of WhatsApp Group was used as a means to support student learning activities outside of school hours. So that it will make children enthusiastic about learning when they are at home. The obstacles faced by parents and teachers in the use of WhatsApp Groups are in the technical part, namely the package quota runs out and internet network disturbances, the ethics of using groups in the WhatsApp Group application, the lack of response from students' parents due to their busy lives and there are still parents who do not understand the information. given from the teacher to the parents of students.
\end{abstract}

Keywords: Communication, Parents, Teachers, WhatsApp Group.

\begin{abstract}
Abstrak
Seiring perkembangan teknologi dan kemunculan berbagai platform komunikasi, interaksi dapat lebih mudah dilakukan. Terlebih di masa belajar daring, hampir 90\% interaksi edukasi dan non edukasi dilakukan melalui WhatsApp Group. Tujuan penulisan ini adalah untuk mengetahui secara langsung pemanfaatan WhatsApp Group dalam membangun komunikasi orang tua dan guru serta untuk mengetahui kendala yang dihadapi orang tua dan guru dalam pemanfaatan WhatsApp Group di SD IT Teuku Umar. Jenis penelitian ini adalah field research (penelitian lapangan). Teknik pengumpulan data yang digunakan adalah wawancara dan dokumentasi. Teknik analisis data yang digunakan adalah analisis deskriptif. Hasil penelitian menunjukkan bahwa pemanfaatan WhatsApp Group dimanfaatkan sebagai sarana dalam menunjang aktivitas belajar siswa di luar jam sekolah. Sehingga akan membuat anak untuk semangat dalam belajar ketika berada di rumah.
\end{abstract}

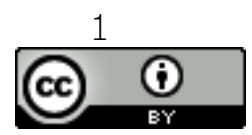

This work is licensed under a Creative Commons Attribution 4.0 International License 
Kendala yang dihadapi orang tua dan guru dalam pemanfaatan WhatsApp Group adalah pada bagian teknis, yaitu kuota paket habis dan gangguan jaringan internet, etika penggunaan grup dalam aplikasi WhatsApp Group, kurang responnya dari orangtua siswa diakibatkan oleh kesibukannya serta masih ada orang tua belum memahami tentang informasi yang diberikan dari pihak guru ke orang tua siswa.

Kata Kunci: Guru, Komunikasi, Orang Tua, Grup WhatsApp

\section{PENDAHULUAN}

Komunikasi menjadi bagian yang tidak terpisahkan dari seluruh aktivitas manusia, baik sebagai individu maupun sebagai kelompok. Indentitas manusia sebagai makhluk sosial mengharuskan manusia berhubungan dengan orang lain. Menurut jalaluddin Rakhmat, komunikasi menyentuh segala aspek kehidupan kita. Sebuah penelitian mengungkapkan bahwa 70\% waktu bangun kita gunakan untuk berkomunikasi. Komunikasi menentukan kualitas hidup (Aziz, 2017; Rakhmat, 2011).

Komunikasi adalah proses penyampaian makna dalam bentuk gagasan atau informasi dari seseorang kepada orang lain melalui media tertentu (Naim, 2011). Tanpa adanya komunikasi, sejarah peradaban manusia tak akan dapat maju sebagaimana tak ada hubungan yang memungkinkan informasi/pesan dapat dibagikan yang membuat informasi/wawasan/pesan dapat tersampaikan (Khoiruddin, 2012).

Media sosial di era digital ini dapat dengan mudah diakses oleh remaja, orang tua, guru, dan lain-lainnya melalui smartphone mereka dengan cara mengunduh aplikasi mobile tersebut kapan pun dan dimana pun (Afnibar \& N, 2020; Mei Yusmita Dkk, 2014; Mubarak, Suyatna, \& Ali Alamsyah Kusumadinata, 2019). Aplikasi media sosial yang sangat terpopuler saat ini melalui WhatsApp dengan ini dimudahkan dalam kegiatan interaksi dan komunikasi (Aulianto, 2019; Sartika, 2018).

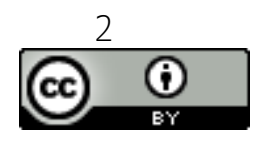

This work is licensed under a Creative Commons Attribution 4.0 International License 
WhatsApp merupakan sebuah aplikasi media sosial yang dirancang untuk memudahkan penggunaannya dalam berkomunikasi melalui berbagai macam fitur yang tersedia. Beberapa fitur yang ada pada aplikasi WhatsApp antara lain Chat Group, WhatsApp Web dan Desktop, Panggilan Suara dan Video WhatsApp, Enskripsi End-To-End, Pengiriman Foto dan Video, Pesan Suara, dan Dokumen. Media sosial WhatsApp melalui beragam fitur yang disediakan dapat digunakan untuk kegiatan yang lebih bermanfaat, misalnya untuk pendidikan(Abdulhak \& Darmawan, 2015). Media sosial WhatsApp merupakan salah satu program alat komunikasi antara guru dan orang tua wali siswa menjadi satu kesatuan dengan cepat dan mudah sehingga informasi apapun baik mengenai program, kegiatan, undangan dan evaluasi siswa dapat disampaikan melalui media sosial pada zaman now (Warsita, 2008).

Melalui WhatsApp Group para orang tua wali siswa mampu bergerak dan berkembang cepat dalam memahami dan mengikuti semua program sekolah dengan tertib dan sempurna (Kahar \& Megawati, 2017; Pusitaningtyas, 2016). Hal-hal yang menjadi dasar pentingnya penggunaan media sosial di Sekolah antara lain, untuk meningkatkan daya komunikasi yang lebih cepat dan tertib antar orang tua wali siswa dengan guru. Juga menambah motivasi orang tua wali siswa untuk mengikuti perkembangan alat komunikasi canggih di zaman sekarang (Syaifullah \& Suparmini, 2019).

Mengingat pentingnya media sosial WhatsApp dalam dunia pendidikan, untuk membantu percepatan akses informasi dan juga terjalinya silaturrahmi antara guru kelas dengan orang tua wali siswa. Maka dengan ini peneliti mengadakan penelitian tentang pemanfaatan WhatsApp Group pada Sekolah IT antara guru kelas dan wali murid. Jika hal tersebut tidak diadakan penelitian maka kita tidak mengetahui sejauh mana manfaat WhatsApp Group

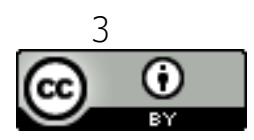

This work is licensed under a Creative Commons Attribution 4.0 International License 
tersebut dan bagaimana isi komunikasi yang terjalin lancar dan baik selama ini. Serta tidak mengetahui pengaruh atau dampak positif dan negatif yang ditimbulkan.

Dengan ini peneliti ingin meneliti sebuah sekolah yang di dalamnya sudah mempunyai WhatsApp Group dalam menjalin hubungan dengan para orang tua wali murid yaitu di SD IT dengan judul "Pemanfaatan Whatsapp Group dalam membangun Komunikasi Orang Tua dan Guru di SD IT Teuku Umar Gampa Kecamatan Johan Pahlawan Kabupaten Aceh Barat".

\section{METODE PENELITIAN}

Jenis penelitian ini adalah penelitian lapangan (field research) melalui pendekatan kualitatif. Subjek penelitian dalam penelitian ini adalah 20 orang guru kelas, 20 orang tua siswa di SD IT. Teknik pengumpulan data yang digunakan adalah wawancara dan dokumentasi. Data yang terkumpul pada penelitian ini adalah data kualitatif, sehingga teknik analisisnya yaitu dilakukan secara interaktif, yang dapat dijelaskan dengan menggunakan langkahlangkah penelitian kualitatif, yaitu reduksi data, penyajian data dan verifikasi data.

\section{HASIL DAN PEMBAHASAN}

\section{a. Pemanfaatan WhatsApp Group Dalam Membangun Komunikasi Orang Tua dan Guru Kelas}

Sekolah merupakan lembaga pendidikan formal tempat berlangsungnya kegiatan belajar mengajar. Dalam kegiatan belajar mengajar tidak lepas dari adanya peran guru, siswa, materi, metode, dan sarana agar tujuan pembelajaran bisa tercapai selain itu peranan motivasi dalam proses pembelajaran juga sangat perlu, baik bersifat intrisik maupun ekstrinsik.

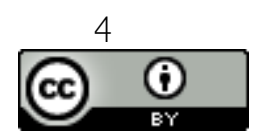

This work is licensed under a Creative Commons Attribution 4.0 International License 
Karena dengan adanya memotivasi siswa dapat mengembangkan aktivitas dan inisiatif dalam melakukan kegiatan pembelajaran, sehingga tujuan dari pembelajaran itu tercapai.

Whatsapp group untuk membangun komunikasi antara orang tua dengan sekolah sehingga orang tua mengetahui perkembangan anaknya selama berada di sekolah. Kelemahan whatsapp group terkadang info yang disampaikan oleh guru jadi kabur karena banyaknya komentar dari wali murid.

Sebagaimana hasil wawancara dengan ibu J yang mengatakan bahwa:

"Kami sebagai orang tua siswa sangat bersyukur dengan adanya whatsApp group ini, karena whatsApp group ini sangat membantu kami dalam menerima informasi dari guru dan kami sebagai orang tua siswa juga bisa menanyakan bagaimana perkembangan anak, apa anak-anak di sekolah melakukan hal-hal yang tidak seharusnya dilakukan, jadi bagi saya sendiri sangat bermanfaat terutama dalam membangun komunikasi orang tua siswa dengan guru. Kendala yang saya dapatkan dalam whatsApp group ini saya kadang merasa pusing dengan banyaknya pesan yang dikirim oleh orang tua siswa yang lain, jadi saya tidak tau lagi yang mana pesan yang penting"

Informasi yang disampaikan guru pada siswa di kelas bisa langsung disampaikan melalui whatsApp group, seperti yang diungkapkan oleh orang tua siswa yang lain yang mengatakan bahwa:

"Manfaat dari adanya whatsApp group ini kemudahannya semua informasi cepat tersampaikan, misalnya besok ada ulangan maka akan di sampaikan melalui whatsApp group tersebut, dan kami dari orang tua siswa juga sangat bersyukur dengan adanya whatsApp group ini akan lebih mudah dalam menjalin komunikasi antara orang tua siswa dan guru. Sejauh ini kalau dalam komunikasi tidak ada kendala, paling kami dari orang tua kadang-kadang tidak ada paket maka ketinggalan informasi"

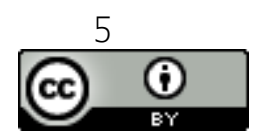

This work is licensed under a Creative Commons Attribution 4.0 International License 
Selanjutnya pemanfaatan whatsapp group dalam membangun komunikasi orang tua dan guru adalah whatsapp group dapat meng-cross chek kondisi anak di sekolah dan di rumah, seperti yang diungkapkan guru wali kelas I, yang mengatakan:

"Manfaatnya adalah dengan adanya whatsapp group ini kita guru kelas merasa lebih puas dan lebih nyaman dalam berkomunikasi dengan orang tua. Karena kami bisa langsung menyampaikan infomasi kepada orang tua melalui lewatkan grup. Melalui whatsapp group lebih efektif dan efisien dalam pekerjaan. Misalkan ada siswa yang tidak masuk sekolah, kami selalu memberi kabar kepada orang tua via telepon, menanyakan kenapa anaknya tidak masuk sekolah. Kalau ada pengumuman jauh lebih cepat dari pada surat yang dititipkan ke anak, habis itu kan hilang juga. Namanya juga anak-anak, tapi kalau sekarang HP ya yang di pegang jadi kalau ada pengumuman lewat whatsapp group akan cepat di tanggapi"

Jadi dapat disimpulkan bahwa, WhatsApp group dimanfaatkan oleh guru dan orang tua dalam:

1. Memberikan kemudahan bagi orang tua dalam mensharing informasi.

2. Membangun komunikasi orang tua dan guru terkait perkembangan perserta didik.

3. Komunikasi orang tua dan guru untuk mempererat silahturahmi.

4. Saling meminta saran dan bertukar pendapat untuk peningkatan mutu pelajaran.

5. Mempermudah guru dan orang tua siswa dalam membangun komunikasi yang baik.

Penggunaan media sosial (whatsApp group) di lingkungan sekolah sudah sangat biasa digunakan, hal ini karena memang maraknya pemakaian gadget dikalangan siswa maupun guru. Penggunaan media sosial tersebut tak jarang timbul banyak masalah yang sering terjadi, hal ini dikarenakan siswa terlalu mengikuti perkembangan globalisasi dan masalah yang sering muncul bagi

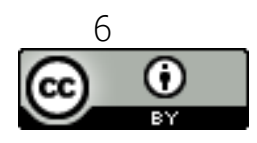

This work is licensed under a Creative Commons Attribution 4.0 International License 
siswa dan guru yang sering terjadi yakni pusatnya berada pada siswa. Sebenarnya dengan adanya kemajuan tehknologi dalam perkembangan globalisasi menjadikan negara kita maju dan tidak ketinggalan zaman. Semua berjalan begitu mudah dan cepat. Namun memang siswa dan guru harus bisa mengimbanginya dan tidak terlalu jatuh dalam keinstanan dan kemudahan tehknologi tersebut.

Melihat maraknya siswa yang terlalu mengikuti perkembangan zaman seperti sekarang membuat wali kelas maupun guru harus lebih bisa mengikuti apa yang diminati oleh siswa. Guru maupun wali kelas harus bisa membuat siswa merasa senang ketika sedang mengikuti pelajaran di kelas agar nilai siswa tidak menurun karena terlalu mengikuti media sosial. Oleh sebab itu, guru maupun wali kelas juga harus memanfaatkan media sosial untuk sarana komunikasi guna mengimbangi siswa, dengan adanya pemanfaatan media sosial whatsApp group tersebut diharapkan siswa mampu mengikuti pelajaran dengan sungguh-sungguh baik dirumah maupun di sekolah.

Pemanfaatan whatsApp group tersebut diharapkan mampu mengontrol kegiatan belajar siswa di luar jam sekolah, seperti yang diungkapkan (Harahap \& Kurniawati, 2018) yang mengatakan bahwa Pemanfaatan adalah aktivitas menggunakan proses dan sumber untuk belajar. Fungsi pemanfaatan sangat penting karena membicarakan kaitan antara peserta didik dengan bahan atau sistem pembelajaran. Pemanfaatan whatsApp group memudahkan guru atau wali kelas untuk mengontrol kegiatan belajar siswa di luar jam sekolah, oleh karena itu guru maupun wali kelas harus menggunakan whatsApp group dalam pembelajaran di sekolah.

Jadi, pemanfaatan whatsapp group memang harus dilakukan di era globalisasi sekarang ini. Karena pada dasarnya whatsApp group memang bertujuan untuk membantu atau mempermudah kegiatan manusia.

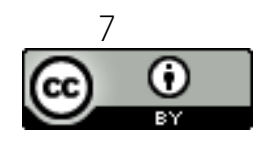

This work is licensed under a Creative Commons Attribution 4.0 International License 
Media sosial sebagai kovergensi antara komunikasi personal dalam arti saling berbagi di antara individu (to be share one-to-one) dan media publik untuk berbagi kepada siapa saja tanpa ada kekhususan individu. Jadi dengan memanfaatkan whatsApp group memang sangat membantu dalam kegiatan komunikasi antar siswa dengan guru atau wali kelas, maupun sebaliknya. Proses pemanfaatan media sosial tersebut dapat berupa dengan guru atau wali kelas mengingatkan tentang tugas siswa, maupun guru atau wali kelas menginfokan pengumuman penting dari sekolah.

Pemanfaatan whatsApp group di kalangan sekolah memang sangat bermanfaat dalam mengikuti perkembangan jaman. Dengan adanya pemanfaatan media sosial tersebut maka wali kelas dalam berperan langsung dalam mengawasi siswa agar tidak terlalu terjerumus dalam kemajuan globalisasi dan tidak terlalu focus dalam pembelajaran di sekolah.

Sebagai seorang guru atau pun wali kelas, maka dituntut untuk kreatif dan inovatif dalam melaksanakan tugasnya. Maka pada sekarang ini sudah banyak yang menggunakan media sosial dalam menunjang kegiaatan belajar. Seperti di sekolah siswa sudah memanfaatkan media sosial untuk berkomunikasi dngan teman lainnya. Hak ini juga membuat guru maupun wali kelas harus memanfaatkan media sosial di dalam kelas seperti pembuatan whatsApp group dalam menunjang aktifitas belajar siswa agar lebih aktif dan bermanfaat dalam menggunakan gadget.

Hal ini karena whatsApp group memang sangat efektif digunakan untuk memudahkan komunikasi. WhatsApp massanger merupakan aplikasi pesan lintas platform yang memungkinkan kita bertukar pesan tanpa biaya sms, karena whatsapp massanger menggunakan paket data internet yang sama untuk email, browsing web, dan lain-lain. Jika dibandingkan dengan aplikasi obrolan online yang lain, whatsApp tetap menjadi aplikasi chatting yang

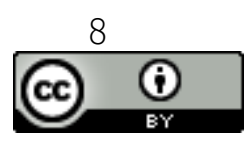

This work is licensed under a Creative Commons Attribution 4.0 International License 
banyak digunakan. Karena dengan adanya pemanfaatan whatsApp tersebut membuat komunikasi menjadi lancar dan efektif digunakan (Suryani, 2017; Trisnani, 2017).

Dalam kegiatan belajar di luar jam sekolah guru ataupun wali kelas dapat mengontrol siswa untuk belajar maupun hanya sekedar mengingatkan bila ada tugas dan pengumuman. Memang kebanyakan siswa bila sudah berada dirumah atau berada dil uar jam sekolah sudah malas untuk belajar dan tidak mengingat akan tugas sekolahnya. Dengan pemanfaatan whatsApp membuat siswa yang pelupa maupun pemalas mempunyai alarm dalam mengingatkan siswa. Ketika siswa memang benar-benar mau belajar dan mengerjakan tugas dari sekolah maka membuat siswa akan lebih aktif di kelas karena sebelumnya sudah mamahami akan pelajaran tersebut. Hal ini berdampak baik pada kegiatan belajar mereka sehingga membuat nilai siswa lebih baik dari sebelumnya yang malas belajar.

Banyak siswa juga yang memanfaatkan whatsapp tersebut untuk sarana berdiskusi dengan teman sekelasnya maupun dengan wali kelas mereka. Berbicara dengan adanya pemanfaatan WhatsApp tersebut memang berdampak baik sebagai penunjang kegiatan siswa di luar jam sekoalah. Banyak siswa yang mengikuti ekstrakurikuler di sekolah sehingga membuat siswa tersebut lupa bahkan kelelahan ketika berada di rumah, namun dengan adanya WhatsApp membuat siswa memiliki pengingat ataupun selalu ada saja siswa yang mengingatkan jika ada tugas.

b. Kendala Yang Dihadapi Orang Tua dan Guru Dalam Pemanfaatan WhatsApp Group di SDIT Teuku Umar Gampa Kecamatan Johan Pahlawan Kabupaten Aceh Barat

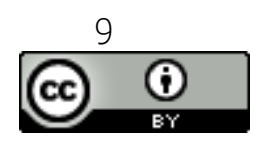

This work is licensed under a Creative Commons Attribution 4.0 International License 
Menurut guru kelas VI, yaitu Bapak J, kendala yang dihadapi orang tua dan guru dalam pemanfaatan whatsapp group di SDIT Teuku Umar Gampa Kecamatan Johan Pahlawan Kabupaten Aceh Barat, yaitu:

"Kendala yang kami dapatkan ketika menggunakan whatsApp group ini adalah dimana sebagia orang tua siswa masih kurang respon dalam whatsApp group dikarenakan sibuk dengan kegiatan dia sendiri dan ada juga orang tua yang mengirim pesan ke whatsApp group pesan yang dianggap tidak penting seperti menjual barang online, karena itu sangat mengganggu pihak yang lain, maka dari itu kami guru kelas menjapri orang tua secara individual untuk tidak mengirim pesan yang tidak bermanfaat dalam pembelajaran siswa. Yang namun dari segi lain terdapat banyak manfaat dan kegunaan dalam menggunakan whatsApp group ini dan sendikit kendala".

Senada dengan pernyataan tersebut di atas, menurut salah seorang orang tua siswa ibu Y juga mengatakan bahwa:

"Adapun kendala yang saya dapatkan ketika saya menggunakan whatsApp group kadang-kadang saya tidak ada paket jadi ketinggalan informasi yang saya dapatkan ataupun jaringan internetnya kurang bagus, itu yang menjadi kendala. Selain itu, karena anak saya masih kelas IV SD, saya belum memberikan Handphone khusus untuk anak saya, jadi sementara ini pakai handphone Mamanya, ya, jadinya harus tunggu mamanya pulang kerja dulu baru bisa anak mengerjakan tugasnya"

Selain kendala yang berkaitan dengan kuota, seringnya beberapa orang tua membagikan informasi yang tidak penting dan tidak ada hubungannya dengan kegiatan sekolah juga menjadi kendala penggunaan whatsapp untuk berkomunikasi. Hal ini menyebabkan informasi yang penting terlewatkan. Selain itu, beberapa orang tua suka acuh terhadap informasi yang didapatkan dari whatsapp grup. Seperti yang disampaikan oleh guru kelas bu S, yang mengatakan bahwa:

"Ya sekarang itu karena komunikasi semakin lancar kemudian setiap individu itu mempunyai grup yang bermacam-macam tentu saja malah informasi yang dibagikan menjadi tertunda karena dia tidak langsung membuka whatsApp group tersebut dan dia angap informasi yang

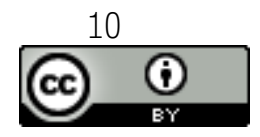

This work is licensed under a Creative Commons Attribution 4.0 International License 
didapatkan itu informasi yang tidak penting. Selain itu dari beberapa anggota grup ada yang membagikan informasi yang tidak ada hubungannya dengan sekolah, jadi beberapa informasi penting menjadi terlewatkan"

Berikut adalah kendala yang dihadapi oleh orang tua siswa dan guru kelas dalam menggunakan WhatsApp Group ialah:

1. Kurangnya paket data (paket internet)

2. Kurang aktifnya sebagian orang tua dalam whatsApp group dikarenakan kesibukan masing-masing

3. Masih adanya orang tua yang belum paham (kurang mengerti)

4. Kurangnya jaringan atau kadang-kadang lelet.

Dalam melakukan hubungan komunikasi secara tidak langsung atau dengan bantuan teknologi tentunya mengalami kendala. Kendala yang sering terjadi adalah kendala non teknis yaitu seperti sering munculnya percakapan yang tidak penting, terutama di whatsApp group baik di grup pribadi maupun grup sekolah. Contohnya, percakapan tentang hal yang bersifat pribadi di dalam whatsApp group dan kadang tidak layak untuk diperbincangkan di ruang publik, dan sering dilakukan tanpa mengenal waktu seperti tengah malam. Hal itu dapat mengganggu anggota grup yang lain. Selain itu, pesan penting yang berhubungan dengan sekolah dapat terabaikan dan kurang diperhatikan. Hal ini dikarenakan kurangnya etika dalam penggunaan grup dalam aplikasi whatsapp oleh orangtua. Selain itu, ada juga kendala lain, yang lebih bersifat teknis seperti kuota pulsa habis dan tidak ada sinyal. Akan tetapi, kendala ini bukanlah kendala yang signifikan.

Hal ini tentu sangat berbeda dengan komunikasi secara langsung. Komunikasi langsung tanpa menggunakan perantara atau media bisa lebih

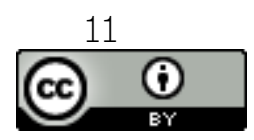

This work is licensed under a Creative Commons Attribution 4.0 International License 
mudah dipahami karena dalam komunikasi ini orang berbicara secara langsung dengan lawan komunikasinya sehingga masalah yang dibicarakan bisa cepat dimengerti dan dipahami. Oleh karena itu, kita bisa memberikan tanggapan langsung terhadap masalah yang sedang dibahas, tidak ada hal yang disembunyikan atau drama komunikasi karena kita berkomunikasi dengan saling bertatap muka. Di lain pihak, komunikasi secara tidak langsung atau menggunakan bantuan teknologi tentu berbeda dengan komunikasi langsung.

Media whatsApp group menjadi faktor pendukung utama dalam pembelajaran daring (Aulianto, 2019). Fasilitas yang memadai sangat penting untuk kelancaran proses belajar mengajar, seperti laptop, komputer ataupun handphone yang akan memudahkan guru untuk memberikan materi belajar mengajar secara daring. Namun di lapangan salah satu penghambat belum semua peserta didik memiliki handphone, sehingga harus menggunakan handphone milik orang tuanya, kemudian rasa malas pada siswa dalam mengerjakan tugas, mekipun sudah didukung dengan fasilitas yang menunjang pembelajaran, orang tua yang bekerja sehingga tidak dapat sepenuhnya membimbing peserta didik dalam pembelajaran daring di rumah.

Tuntutan pekerjaan yang dialami orang tua siswa yang begitu sibuk menyebabkan terhambatnya arus komunikasi antara sekolah dengan orang tua siswa. Oleh karena itu, orang tua tidak bisa selalu memantau perkembangan belajar anaknya di sekolah. Dengan adanya bantuan teknologi, maka pesan atau informasi dapat tersampaikan dengan cepat dan actual (Kahar \& Megawati, 2017; Saulinggi, Tambunan, \& Sulianti, 2013).

Ada beberapa cara untuk mengatasi hambatan tersebut, di antaranya adalah koordinasi dengan orang tua sangat dibutuhkan, sinergitas antara guru dan orang tua harus terjalin guna kelancaran proses pembelajran anak dan

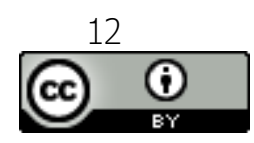

This work is licensed under a Creative Commons Attribution 4.0 International License 
guru juga bias dapat mengontrol siswa dengan baik melalu orang tua. Kemudian guru menganalisis bagi orang tua yang sibuk bekerja, guru harus memberikan pelonggaran dalam pengumpulan tugas.

Pembelajaran daring juga tidak lepas dari peran orang tua peserta didik, karena mengingat usia anak sekolah dasar yang masih perlu bimbingan dan juga pengwasan dalam pembelajaran. Orang tua selalu memberikan informasi baru mengenai perkembangan anaknya dalam proses pembelajaran melalui media whatsApp group di rumah, orang tua selalu memberikan motivasi kepada anaknya, karena pemberian motivasi menjadi sangat berarti bagi peserta siswa, baik oleh guru maupun orang tua siswa hal itu perlu dilakukan agar peserta didik kembali semangat meskipun belajar dari rumah, itulah pentingnya komunikasi antara guru dan orang tua siswa.

\section{c. KESIMPULAN}

Berdasarkan pembahasan dapat disimpulkan bahwa pemanfaatan WhatsApp group dalam membangun komunikasi orang tua dan guru kelas di SD IT Teuku Umar dimanfaatkan sebagai sarana dalam menunjang aktifitas belajar siswa di luar jam sekolah. Melalui WhatsApp group pengawasan dari guru diluar jam sekolah terhadap siswa dapat terbantu melalui komunikasi dengan orang tua siswa dalam menunjang aktifitas belajar siswa di luar jam sekolah, sehingga akan membuat anak untuk semangat dalam belajar ketika berada di dalam rumah.

Adapun Kendala yang dihadapi orang tua dan guru dalam pemanfaatan whatsApp Group di SD IT Teuku Umar Gampa Kecamatan Johan Pahlawan Kabupaten Aceh Barat adalah pada bagian teknis, yaitu kuota paket habis dan gangguan jaringan internet, kurang responnya dari orangtua siswa

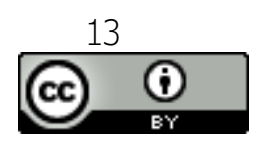

This work is licensed under a Creative Commons Attribution 4.0 International License 


\section{Al-Azkiya: JURHAL ILYIAH PEWDIDIKAK YI/SD}

ISSI: Print (2145-1656) Online (2527-8110) Vol. 6 Ho.12021

diakibatkan oleh kesibukannya serta masih ada orang tua belum memahami tentang informasi yang diberikan dari pihak guru ke orang tua siswa

\section{DAFTAR PUSTAKA}

Abdulhak, I., \& Darmawan, D. (2015). Teknologi Pendidikan. Bandung: Rosda Karya.

Afnibar, \& N, D. F. (2020). Pemanfaatan WhatsApp Sebagai Media Komunikasi Kegiatan Belajar ( Studi terhadap Mahasiswa UIN Imam Bonjol Padang ). Al-Munir: Jurnal Komunikasi Dan Penyiaran Islam, 11(1), 70-83.

Aulianto, D. R. (2019). WHATSAPP SEBAGAI MEDIA KOMUNIKASI (Studi Fenomenologi Motif Pengaturan Privasi Chatting Pengguna Whatsapp dalam Komunikasi Antarpribadi). Jurnal Komunikasi Dan Media, 3(2 Februari), 150-158.

Aziz, A. (2017). Komunikasi pendidik dan peserta didik dalam pendidikan islam. Mediakita, 1(2 Juli), 173-184.

Harahap, H. S., \& Kurniawati, D. I. (2018). WhatsApp Sebagai Media Strategi Komunikasi Ustadzah dalam Menyampaikan Dakwah ( Studi Deskriptif Kualitatif Komunitas "Belajar Islam Seru "). DiMCC Conference Proceeding, 1, 131-150. Kahar, F., \& Megawati. (2017). Pengaruh Komunikasi Orang Tua Dengan Guru terhadap Peningkatan Kualitas Pembelajaran. Jurnal Office, 3(1), 33-42.

Khoiruddin, M. A. (2012). Peran Komunikasi dalam Pendidikan. Komunikasi, 23(1), 118-131.

Mei Yusmita Dkk. (2014). Pemanfaatan WhatsApp Messenger Sebagai Media Kumunikasi Antar Pribadi Mahasiswa IImu Komunikasi.

Mubarak, F., Suyatna, U., \& Ali Alamsyah Kusumadinata. (2019). Fungsi Media Sosial Grup WhatsApp Sebagai Media Komunikasi Guru Sekolah Alam Komunitas Fitrah Lebah. Jurnal Komunikasi Dan Media, 3(2), 175-179.

Naim, N. (2011). Dasar-dasar Komunikasi Pendidikan (A. R. Media, ed.). Yogyakarta.

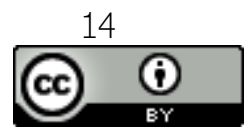

This work is licensed under a Creative Commons Attribution 4.0 International License 
Pusitaningtyas, A. (2016). Pengaruh Komunikasi Orang Tua dan Guru Terhadap Kreativitas Siswa. Proceeding of ICECRS, 1(14), 935-942. https://doi.org/http://dx.doi.org/10.21070/picecrs.v1i1.632

Rakhmat, J. (2011). Metode Penelitian Komunikasi. Bandung: Remaja Rosda Karya.

Sartika. (2018). Kegunaan WhatsApp Sebagai Media Informasi dan Media STISIP Persada Bunda. Medium, 6(2), 15-26.

Saulinggi, S., Tambunan, E. B., \& Sulianti, N. (2013). Hubungan Antara Komunikasi Guru-Orang Tua dan Profesionalisme Guru dengan Motivasi Berprestasi Siswa Primarydi Global Jaya International School Bintaro Tangerang. 2(1), 100-113.

Suryani, R. (2017). Fungsi Whatsapp Grup Shalihah Cabang Bandar Lampung Sebagai Pengembangan Media Dakwah Dalam Membentuk Akhlakul Karimah (Institut Agama Islam Negeri Raden Intan Lampung). Retrieved from http://repository.radenintan.ac.id/779/

Syaifullah, J., \& Suparmini. (2019). Pemanfaatan Media Sosial WhatsApp Sebagai Masjid Indonesia Desa Gedongan Kecamatan Colomadu Kabupaten Karanganyar. Indonusa Conference on Technologi and Social 2019, (November), 158-167. Politeknik SUrakarta.

Trisnani. (2017). Pemanfaatan Whatsapp Sebagai Media Komunikasi Dan Kepuasan Dalam Penyampaian Pesan Dikalangan Tokoh Masyarakat. Jurnal Komunikasi, Media Dan Informatika, 6(3), 1-12. https://doi.org/10.31504/komunika.v6i3.1227

Warsita, B. (2008). Teknologi Pembelajaran. Jakarta: PT. Rineka Cipta.

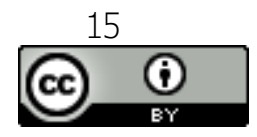

